\title{
Ten-year survival rate after rotational acetabular osteotomy in adulthood hip dysplasia
}

Masamitsu Tomioka, Yutaka Inaba*, Naomi Kobayashi, Taro Tezuka, Hyonmin Choe, Hiroyuki Ike and Tomoyuki Saito

\begin{abstract}
Background: Rotational acetabular osteotomy (RAO) is an effective joint-preserving surgical treatment for adulthood hip dysplasia (AHD). Despite sufficient correction of acetabular dysplasia, some patients still experience osteoarthritis (OA) progression and require total hip arthroplasty (THA). The purposes of the current study were to investigate the survival rate and the risk factors for OA progression or THA requirement after RAO and to explore whether acetabular overcorrection relates to OA progression.

Methods: Fifty-six patients (65 hips, mean age: $36.5 \pm 11.7$ years) with AHD who underwent RAO and were followed up for $>10$ years (mean: $15.0 \pm 3.2$ years) were enrolled in this study. A Kaplan-Meier survival analysis was performed to assess the non-OA progression rate and THA-free survival rate of RAO during the 10-year follow-up. To analyze the risk factors for OA progression and THA requirement, the Cox proportional hazards regression analysis was performed.

Results: No OA progression was found in 76.7\% of the patients, and THA was not required in $92.3 \%$ during the 10year follow-up. By multivariate regression analysis, older age at the time of surgery was a risk factor for both OA progression (hazard ratio $[H R]=1.047,95 \%$ confidence interval $[\mathrm{Cl}]=1.005-1.091)$ and THA requirement $(H R=1.293$, $95 \% \mathrm{Cl}=1.041-1.606)$.

Conclusion: RAO is an effective surgical procedure for symptomatic patients with AHD that prevents OA progression and protects the hips from undergoing THA. However, older patients have a higher risk for both OA progression and THA requirement.
\end{abstract}

Keywords: Rotational acetabular osteotomy, Adulthood hip dysplasia, Osteoarthritis, Survival analysis, Risk factors

\section{Background}

Adulthood hip dysplasia (AHD) is a hip condition that causes hip pain and osteoarthritis (OA). AHD is one of the major causes of hip OA in the Japanese population [1]. Dysplastic acetabular roof induces instability and incongruence of the hip joints at an early age that trigger the progression of hip OA and may require total hip arthroplasty (THA) even in young- or middle-aged patients. Since THA for young- or middle-aged active patients is associated with high rates of loosening [2,3], joint-preserving operations are an important surgical option.

\footnotetext{
* Correspondence: yute0131@med.yokohama-cu.ac.jp

Department of Orthopedic Surgery, Yokohama City University, 3-9 Fukuura, Kanazawa-ku, Yokohama, Japan
}

(c) The Author(s). 2017 Open Access This article is distributed under the terms of the Creative Commons Attribution 4.0 International License (http://creativecommons.org/licenses/by/4.0/), which permits unrestricted use, distribution, and reproduction in any medium, provided you give appropriate credit to the original author(s) and the source, provide a link to the Creative Commons license, and indicate if changes were made. The Creative Commons Public Domain Dedication waiver (http://creativecommons.org/publicdomain/zero/1.0/) applies to the data made available in this article, unless otherwise stated. preserving periacetabular osteotomy technique [4-8] developed by Ninomiya and Tagawa [9] that corrects insufficient femoral coverage by rotating the acetabular roof with an articular cartilage. RAO remains a successful treatment for patients with AHD with careful selection of indications [10]. However, some reported that older age at the time of surgery is associated with lower success rates in this procedure [11]. Since many factors affect the outcome of RAO, the optimal indication is still controversial, especially in middle-aged patients. Appropriate surgical technique and patient selection are important factors for successful outcomes. Undercorrection of the acetabular roof may result in instabilities of the hip joint, 
and efficient coverage of the acetabular roof to the femoral head is essential in this procedure. However, overcorrection of the acetabular roof may lead to pincer impingement and accelerate OA progression. Association of overcorrection and OA progression after RAO was rarely investigated previously $[6,12]$.

The purposes of the current study were to investigate the 10-year survival rate and risk factors for OA progression or THA requirement after RAO and whether overcorrection of the acetabular roof accelerates OA progression in our patients.

\section{Methods}

The study was approved by the authors' institutional review board (Yokohama City University, \#B170100004), and informed consent for participating the current study and for publication was obtained from all patients. Fiftysix patients ( 4 men, 52 women; 65 hips) who underwent RAO at our institution and were followed up for $>$ 10 years were enrolled in the current study. Indications of the surgery were as follows: 1 . age $<60$ years, 2 . progressive pain that interferes with daily activities, 3. center edge ( $\mathrm{CE}$ angle $)<20^{\circ}$, and 4 . improvement of the femoral head coverage and joint congruity in a hip abduction position on anteroposterior hip radiography. One patient (1 hip) had a neurological disorder due to cerebral palsy as a comorbidity. In these 56 patients, preoperative and postoperative radiographs, medical records, and operative reports were reviewed retrospectively. In cases with deformities of the femoral head, we performed intertrochanteric femoral varus or valgus osteotomy combined with RAO to improve the joint congruency. In the current study, 11 hips of 10 patients had a simultaneous intertrochanteric osteotomy. One had a varus osteotomy, and the other 10 hips had a valgus osteotomy.

As an operative technique and rehabilitation, a 15 to $20 \mathrm{~cm}$ straight incision was made from the distal aspect of the greater trochanter toward the iliac crest. In order to approach the superior aspect of the acetabulum, a transtrochanteric approach was performed. The osteotomy line of the acetabulum was marked at about $1.5 \mathrm{~cm}$ from the acetabular rim, and an osteotome was inserted to a depth of about $1.0 \mathrm{~cm}$ without penetrating the joint. A curved osteotome was then used to avoid penetrating the inner wall of the ilium, and the osteotomy was performed around the circumference of the acetabulum. Adequate coverage of the femoral head was achieved by moving the resected acetabulum laterally and anteriorly to make a $0^{\circ}$ acetabular roof obliquity (AC angle). Two or 3 absorbable screws were used to fix the rotated acetabulum to the ilium. The greater trochanter was reattached using 2 absorbable screws; one was $6.5 \mathrm{~mm}$ and the other was $4.5 \mathrm{~mm}$ in diameter, and the screws were fixed bicortically. In cases of an additional trochanteric valgus osteotomy, we exposed the proximal shaft of the femur and inserted the screw toward the femoral head at the predetermined insertion angle under image intensification. Thereafter, lateral wedge osteotomy was performed at the level of the lesser trochanter. After removal of the lateral wedge and subsequent valgization, the removed wedge bone was implanted between the femur and resected greater trochanter to restore the femoral offset. The distal femur was then fixed with a plate and the greater trochanter with 2 pairs of pins and cables.

Transfer in a wheelchair was begun 1 week after surgery. One-third weight-bearing positions were allowed at 3 weeks, half weight-bearing at 5 weeks, and full weight walking at 8 weeks after surgery.

Need for THA because of a painful hip after RAO was defined as the clinical end point of the follow-up. The OA stage was radiographically divided into 4 stages, according to the classification of the Japanese Orthopedic Association (JOA) (Prearthritis: acetabular dysplasia without osteoarthritic changes; Early stage: slight narrowing of the joint space associated with sclerosis of the subchondral bone; Advanced stage: narrowing of the joint space with cystic lucencies and small osteophytes; and End stage: disappearance of the joint space and marked osteophyte formation) [4]. The diagnosis of OA progression was made by comparing the OA stage before surgery and at the final follow-up.

Anteroposterior hip radiographic assessments in the supine position were conducted. A single well-trained orthopedic surgeon, who was blinded from the clinical results, performed all radiographic measurements. For the assessment of acetabular coverage on the femoral head, CE angle, sharp angle, acetabular femoral head index, and $\mathrm{AC}$ angle were quantified. Joint space width (JSW), presence of cysts, deformity of the femoral head, and thickness of the transferred acetabulum at the widest portion were also measured. Obturator foramenhead distance, which is the distance from the lateral side of the obturator foramen to the medial side of the femoral head that represents an index of medialization of the hip, was also quantified. The abovementioned radiographic assessments were conducted before and immediately after surgery. Radiographic assessment of acetabular coverage was also performed at the final follow-up.

We also assigned our patients to two groups: the overcorrection and non-overcorrection groups, according to the anteroposterior hip radiographic measurement using the CE angle immediately after RAO [13]; we defined overcorrection as a $\mathrm{CE}$ angle $>40^{\circ}$ and non-overcorrection as a $\mathrm{CE}$ angle $\leq 40^{\circ}$ according to the reports of Chung et al. [14] Survival rates for $\mathrm{OA}$ progression and THA requirement in the 
overcorrection and non-overcorrection groups were compared.

We also evaluated the influence of smoking on the result of RAO. Patients were also divided into nonsmokers and smokers, according to the Center for Disease Control and Prevention guidelines to assess the risk of nicotine abuse [15].

A Kaplan-Meier survival analysis was performed to assess the non-OA progression rate and THA-free survival rate of RAO during the 10 -year follow-up. To analyze the risk factors for OA progression and THA requirement, the Cox proportional hazards regression analysis was performed. Cox regression analysis was firstly performed univariately on potential risk factors. Furthermore, risk factors that indicate significant $p$ values $<0.05$ were populated for the Cox regression analysis as a multivariate assessment. We calculated the cut off points of each variable which indicated significant $p$ value $<$ 0.05 for both THA requirement and OA progression with the receiver operating characteristic (ROC) curve. To analyze the time course difference of mean normal variance data, the paired $t$-test was performed. To analyze the influence of an additional intertrochanteric valgus or varus osteotomy, we performed a log-rank analysis and compared the non-OA progression rate and THA-free survival rate of RAO. A $p$ value $<0.05$ was considered statistically significant. All analyses were performed using the SPSS version 22.0 (IBM, Armonk, NY, USA).

\section{Results}

The mean age at the time of surgery was $36.5 \pm 11.7$ years (range, 11-56 years). The mean body mass index was $21.2 \pm 2.3 \mathrm{~kg} / \mathrm{m}^{2}$ (range, $16.9-33.5 \mathrm{~kg} / \mathrm{m}^{2}$ ). Twelve patients $(21.4 \%)$ were smokers. Ten patients (11 hips) were treated with intertrochanteric valgus or varus osteotomy simultaneous to the RAO procedure to improve joint congruency. The average follow-up period was $15 \pm$ 3.2 years (range, 10-22.5 years). In all hips, coverage of the acetabulum on the femoral head improved after surgery (Table 1).

According to the JOA classification for OA grades, there were 46 Prearthritis, 15 Early, 4 Advanced, and no End stage cases, preoperatively. The 10-year unadjusted
Kaplan-Meier survival rate of RAO for THA requirement was $92.3 \%$ (Fig. 1a). OA stage progressed in 15 hips during the 10-year follow-up, which included 5 THAs, and the 10-year survival rate for OA stage progression was $76.7 \%$ (Fig. 1b). To investigate the risk factors for OA progression or THA requirement, the Cox proportional hazards regression analysis was utilized. From the univariate Cox regression analysis of risk factors for THA requirement, age at the time of surgery, preoperative JSW, and radiographic stage indicated $\mathrm{p}$ values $<0.05$. The Cox multivariate regression analysis revealed that the age at the time of surgery was an independent risk factor for THA requirement (hazard ratio $[\mathrm{HR}]=1.293, p=0.020$, 95\% confidence interval $[\mathrm{CI}]=$ 1.041-1.606) (Table 2). For the univariate Cox regression analysis, age at the time of surgery and thickness of the transferred acetabulum were significant risk factors for OA progression. However, the Cox multivariate regression analysis showed only age at the time of surgery as the independent risk factor for $\mathrm{OA}$ progression $(\mathrm{HR}=$ 1.047, $p=0.028,95 \% \mathrm{CI}=1.005-1.091$ ) (Table 3). We calculated the cut off points of age at the time of surgery for both THA requirement and OA progression with the ROC curve. The ROC curve showed the cut off points of 43.5 years for THA requirement (sensitivity: $87.5 \%$; specificity: $66.7 \%$ ) and 38.5 years for OA progression (sensitivity: 67.6\%; specificity: 64.5\%). Since age was found to be an important risk factor for poor outcomes in RAO, we divided all patients into 2 groups by age: $>41$ years (older age group) and $\leq 41$ years (younger age group), according to the average of the cut off points calculated above. Seven hips required THA in the older age group during the 10-year follow-up and 1 hip in the younger age group. A log-rank analysis showed a significantly worse survival rate in the older age group for both OA progression and THA requirement (Fig. 2).

There was no significant difference in the THA-free survival rate between the overcorrection group and the non-overcorrection group in the OA progression survival rate during the 10-year follow-up (Fig. 3). We then compared the time course change in the $\mathrm{CE}$ angles in both groups. Interestingly, the CE angle significantly decreased over time in the overcorrection group but not in the non-overcorrection group (Fig. 4). It is likely because

Table 1 Radiological measurements of acetabular coverage of the femoral head before and after surgery

\begin{tabular}{|c|c|c|c|}
\hline & Preoperative & Immediately after surgery & $p$ value (paired $t$-test) \\
\hline Center edge angle $\left(^{\circ}\right)$ & $6.0 \pm 10.7$ & $49.9 \pm 13.1$ & $<0.001$ \\
\hline Sharp angle $\left(^{\circ}\right)$ & $48.9 \pm 4.1$ & $32.5 \pm 7.7$ & $<0.001$ \\
\hline Acetabular head index (\%) & $56.8 \pm 10.1$ & $97.9 \pm 10.8$ & 0.001 \\
\hline Acetabular roof obliquity $\left(^{\circ}\right)$ & $27.2 \pm 6.8$ & $0.0 \pm 12.1$ & $<0.001$ \\
\hline Obturator foramen-head distance (mm) & $17.5 \pm 3.5$ & $15.6 \pm 4.6$ & 0.006 \\
\hline
\end{tabular}



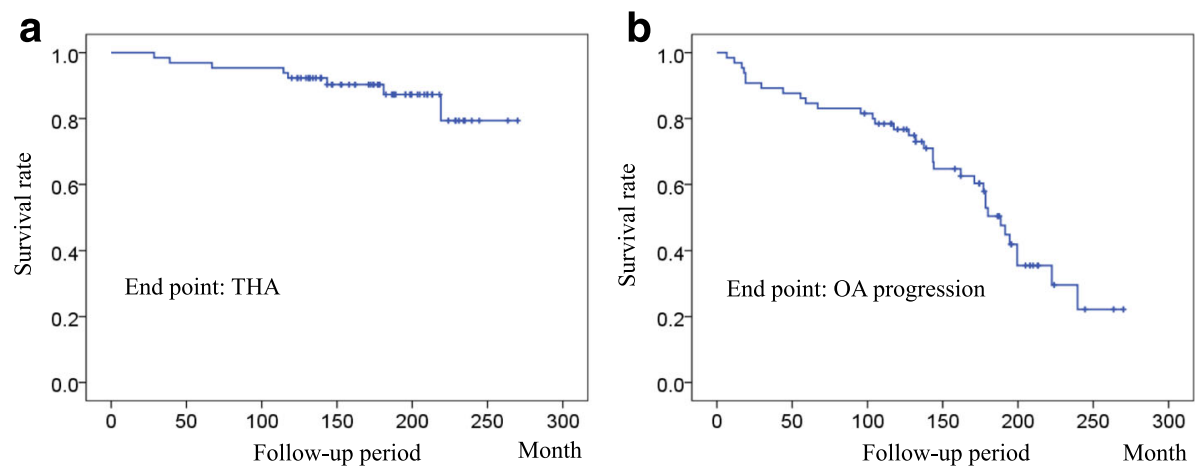

Fig. 1 Kaplan-Meier survival analysis of rotational acetabular osteotomy for total hip arthroplasty (THA) requirement and osteoarthritis (OA) progression. During the 10-year follow-up, $92.3 \%$ of the hips did not need THA (a), and OA progression was not seen in 76.7\% of the hips after RAO (b) (numbers at risk $=65$ hips)

Table 2 Risk factors for THA requirement after RAO assessed by univariate and multivariate regression analyses

\begin{tabular}{|c|c|c|c|}
\hline Variables & Hazard ratio & 95\% Confidence Interval & $p$ value \\
\hline \multicolumn{4}{|l|}{ Univariate regression } \\
\hline \multicolumn{4}{|l|}{ Preoperative } \\
\hline Age at the time of surgery & 1.248 & $1.059-1.471$ & 0.008 \\
\hline Body mass index & 0.986 & $0.711-1.369$ & 0.934 \\
\hline Smoking history & 0.036 & $0.000-67.106$ & 0.386 \\
\hline Presence of cysts & 7.329 & $0.900-59.685$ & 0.063 \\
\hline Deformity of the femoral head & 0.515 & $0.063-4.208$ & 0.536 \\
\hline Center edge angle $\left(^{\circ}\right)$ & 0.958 & $0.909-1.011$ & 0.119 \\
\hline Sharp angle $\left(^{\circ}\right)$ & 1.056 & $0.892-1.250$ & 0.527 \\
\hline Acetabular head index (\%) & 0.964 & $0.909-1.022$ & 0.220 \\
\hline Acetabular roof obliquity $\left(^{\circ}\right)$ & 1.023 & $0.923-1.134$ & 0.662 \\
\hline Obturator foramen-head distance (mm) & 1.200 & $0.972-1.481$ & 0.091 \\
\hline Joint space width (mm) & 0.655 & $0.449-0.957$ & 0.029 \\
\hline Radiographic stage & 2.691 & $1.205-6.013$ & 0.016 \\
\hline \multicolumn{4}{|l|}{ Immediately after the surgery } \\
\hline Center edge angle $\left(^{\circ}\right)$ & 0.996 & $0.944-1.052$ & 0.896 \\
\hline Sharp angle $\left(^{\circ}\right)$ & 1.058 & $0.969-1.154$ & 0.206 \\
\hline Acetabular head index (\%) & 0.992 & $0.931-1.057$ & 0.803 \\
\hline Acetabular roof obliquity $\left(^{\circ}\right)$ & 1.023 & $0.966-1.083$ & 0.435 \\
\hline Obturator foramen-head distance (mm) & 0.982 & $0.838-1.152$ & 0.828 \\
\hline Joint space width (mm) & 0.674 & $0.428-1.060$ & 0.088 \\
\hline Radiographic stage & 1.693 & $0.664-4.317$ & 0.271 \\
\hline Joint congruity & 1.981 & $0.898-4.372$ & 0.091 \\
\hline Thickness of the transferred acetabulum & 0.991 & $0.848-1.159$ & 0.911 \\
\hline \multicolumn{4}{|l|}{ Multivariate regression } \\
\hline Age at the time of surgery & 1.293 & $1.041-1.606$ & 0.020 \\
\hline Preoperative Joint space width & 1.327 & $0.533-3.301$ & 0.543 \\
\hline Radiographic stage & 4.155 & $0.413-41.812$ & 0.227 \\
\hline
\end{tabular}


Table 3 Risk factors for OA progression after RAO assessed by univariate and multivariate regression analyses

\begin{tabular}{|c|c|c|c|}
\hline Variables & Hazard ratio & 95\% Confidence Interval & $p$ value \\
\hline \multicolumn{4}{|l|}{ Univariate regression } \\
\hline \multicolumn{4}{|l|}{ Preoperative } \\
\hline Age at the time of surgery & 1.051 & $1.011-1.093$ & 0.013 \\
\hline Body mass index & 0.996 & $0.847-1.170$ & 0.957 \\
\hline Smoking history & 0.555 & $0.213-1.451$ & 0.230 \\
\hline Presence of cysts & 1.398 & $0.710-2.752$ & 0.333 \\
\hline Deformity of the femoral head & 0.895 & $0.389-2.063$ & 0.795 \\
\hline Center edge angle $\left(^{\circ}\right)$ & 0.998 & $0.962-1.035$ & 0.911 \\
\hline Sharp angle $\left(^{\circ}\right)$ & 0.961 & $0.888-1.039$ & 0.315 \\
\hline Acetabular head index (\%) & 1.000 & $0.963-1.037$ & 0.981 \\
\hline Acetabular roof obliquity $\left(^{\circ}\right)$ & 1.015 & $0.965-1.067$ & 0.572 \\
\hline Obturator foramen-head distance (mm) & 1.074 & $0.970-1.188$ & 0.169 \\
\hline Joint space width (mm) & 0.961 & $0.819-1.126$ & 0.621 \\
\hline Radiographic stage & 1.028 & $0.664-1.592$ & 0.902 \\
\hline \multicolumn{4}{|l|}{ Immediately after the surgery } \\
\hline Center edge angle $\left({ }^{\circ}\right)$ & 0.996 & $0.971-1.023$ & 0.783 \\
\hline Sharp angle $\left(^{\circ}\right)$ & 1.014 & $0.972-1.058$ & 0.520 \\
\hline Acetabular head index (\%) & 1.001 & $0.969-1.035$ & 0.935 \\
\hline Acetabular roof obliquity $\left(^{\circ}\right)$ & 0.999 & $0.974-1.026$ & 0.959 \\
\hline Obturator foramen-head distance (mm) & 0.925 & $0.855-1.001$ & 0.052 \\
\hline Joint space width (mm) & 0.953 & $0.763-1.189$ & 0.669 \\
\hline Radiographic stage & 0.808 & $0.459-1.425$ & 0.462 \\
\hline Joint congruity & 0.997 & $0.680-1.460$ & 0.986 \\
\hline Thickness of the transferred acetabulum & 0.887 & $0.800-0.982$ & 0.022 \\
\hline \multicolumn{4}{|l|}{ Multivariate regression } \\
\hline Age at the time of surgery & 1.047 & $1.005-1.091$ & 0.028 \\
\hline Thickness of the transferred acetabulum & 0.923 & $0.829-1.027$ & 0.142 \\
\hline
\end{tabular}

$N=65$ hips

$O A$ osteoarthritis, $R A O$ rotational acetabular osteotomy
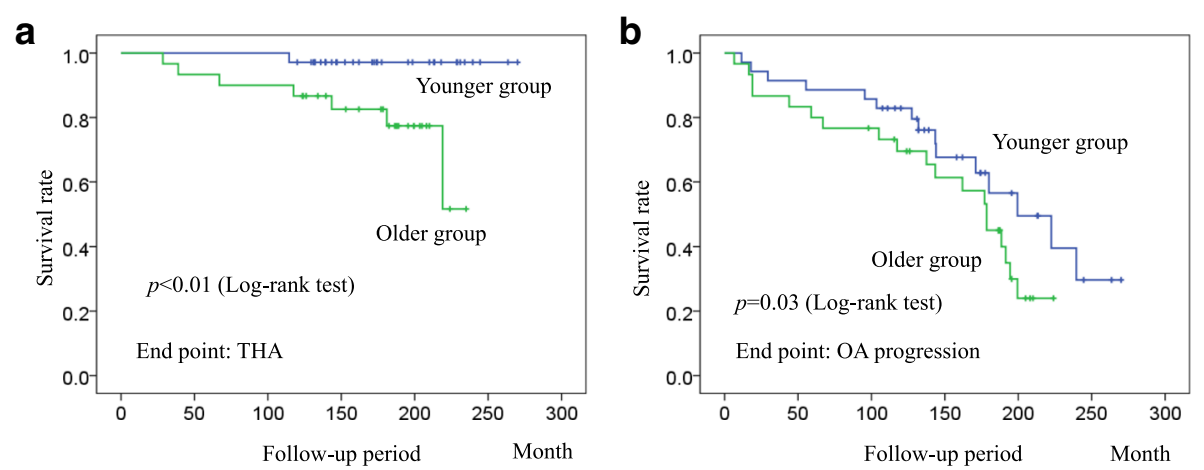

Fig. 2 Kaplan-Meier survival analysis of rotational acetabular osteotomy for total hip arthroplasty (THA) requirement and osteoarthritis (OA) progression in the patients older than 41 years (older age group) and younger than 41 years (younger age group). The younger age group had significantly better THA-free survival rate (a) and OA progression rate (b) than the older age group during the 10-year follow-up (numbers at risk $=65$ hips in the younger and older age groups) (Log-rank test, $p<0.01$ and 0.03 , respectively) 

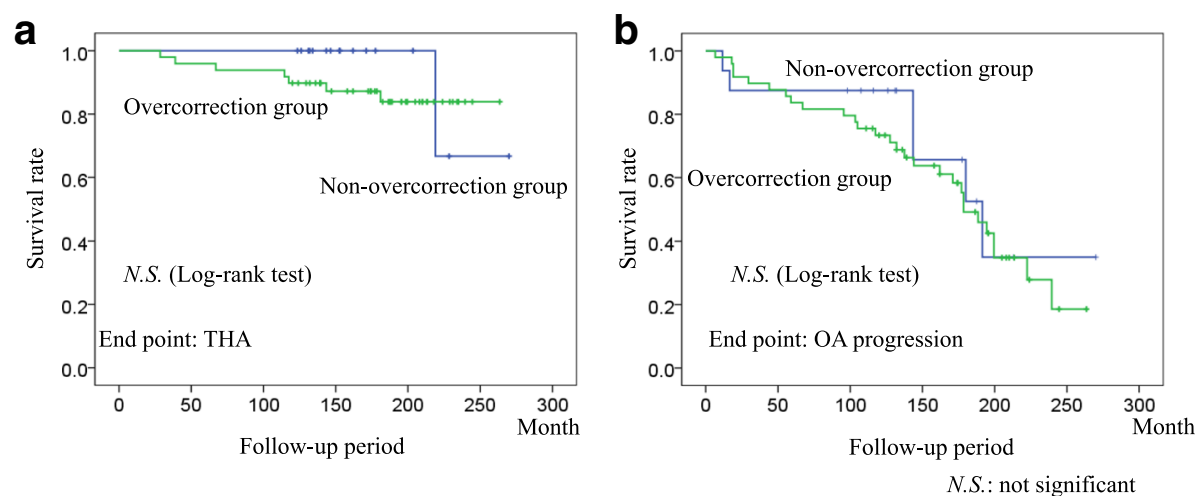

Fig. 3 Kaplan-Meier survival analysis of rotational acetabular osteotomy for total hip arthroplasty (THA) requirement and osteoarthritis (OA) progression in the patients with postoperative center edge (CE) angle $\leq 40^{\circ}$ (non-overcorrection group) and $>40^{\circ}$ (overcorrection group). There was no significant difference in the THA-free survival rate between the 2 groups (a) and in the OA progression survival rate (b) during the 10-year follow-up (numbers at risk $=65$ hips in the non-overcorrection and overcorrection groups)

the portion of the overhanging in the acetabular roof after RAO was not loaded in daily life that attributed remodeling and resulted in resorption of the overcorrected acetabular roof.

There were no cases of intraoperative and early postoperative complications, such as major neurovascular complications, chisel perforation into the joint, thrombosis of the deep vein, postoperative movement of a rotated acetabulum, and delayed union of the osteotomy site. Further, there was no significant relationship between smoking and the result of RAO.

There was no significant difference in the THA-free survival rate $(p=0.10)$ nor in the non-OA progression rate $(p=0.15)$ among the patients treated with RAO alone, RAO with valgus osteotomy, and RAO with varus osteotomy.

Figure 5a shows the radiographic image of a 24-yearold woman who presented to our department with a history of coxalgia on her right hip, which gradually

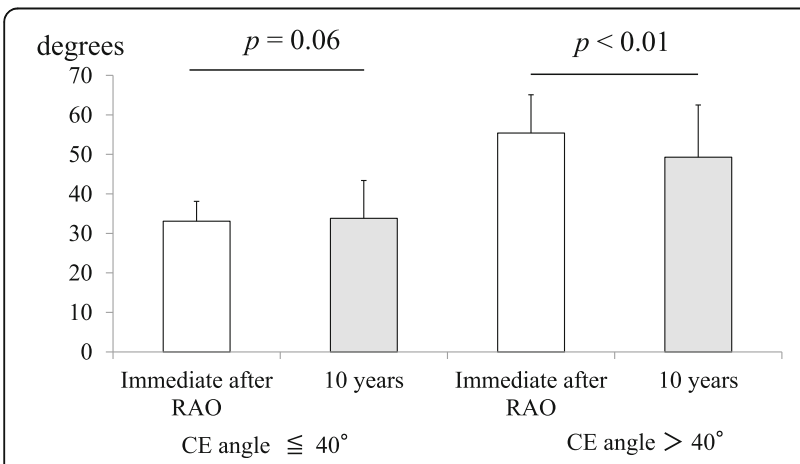

Fig. 4 Time course change of center edge (CE) angle and representative radiographs of the patients in the overcorrection group after rotational acetabular osteotomy (RAO). CE angle immediately after RAO significantly decreased with time in the overcorrection group $(55.4 \pm 9.7$ to $49.3 \pm 13.2, p<0.01)$ but not in the non-overcorrection group $(33.1 \pm 5.0$ to $33.8 \pm 9.6, p=0.06)$ deteriorated. The plane radiographic image of the hip showed AHD; however, the joint cartilage was preserved. Figure $5 \mathrm{~b}$ shows the radiographic image immediately after RAO in which the coverage of the femoral head improved. Figure 5c shows the radiographic image 12 years after RAO; she did not have any symptoms on her left hip, and there was no joint space narrowing. Figure 6a shows the plane radiographic image of a 25-yearold woman with AHD and deformity of the femoral head. The joint space became wider when the hip was adducted, and the position of the loading area of the femoral head became horizontal (Fig. 6b); thus, we performed RAO with valgus femoral osteotomy (Fig. 6c). Figure $6 \mathrm{~d}$ shows the radiographic image 10 years after the surgery; there was no progression of OA compared with the finding immediately after surgery. She had no pain or other complaints on her left hip.

\section{Discussion}

$\mathrm{RAO}$ is one of the well-established osteotomies for patients with AHD [4-9, 16, 17]. However, even with this success rate of this surgery, some patients still experience hip pain or progressive OA that may require THA, especially in middle-aged patients [18-25]. Therefore, the primary purpose of the current study was to investigate the risk factors for poor RAO treatment outcomes. For this purpose, we firstly investigated the long-term outcomes of RAO in our institution and found that RAO is a successful treatment for AHD that allows more than $90 \%$ of the hips to not required arthroplasty for $>10$ years. Several authors also reported the longterm follow-up results of RAO. The 10-year survival rate in the current study was lower than that previously reported. It is likely because the mean age at the time of surgery in this study was 36.5 years, which is a little older than that in other reports $[11,26]$. Several authors 


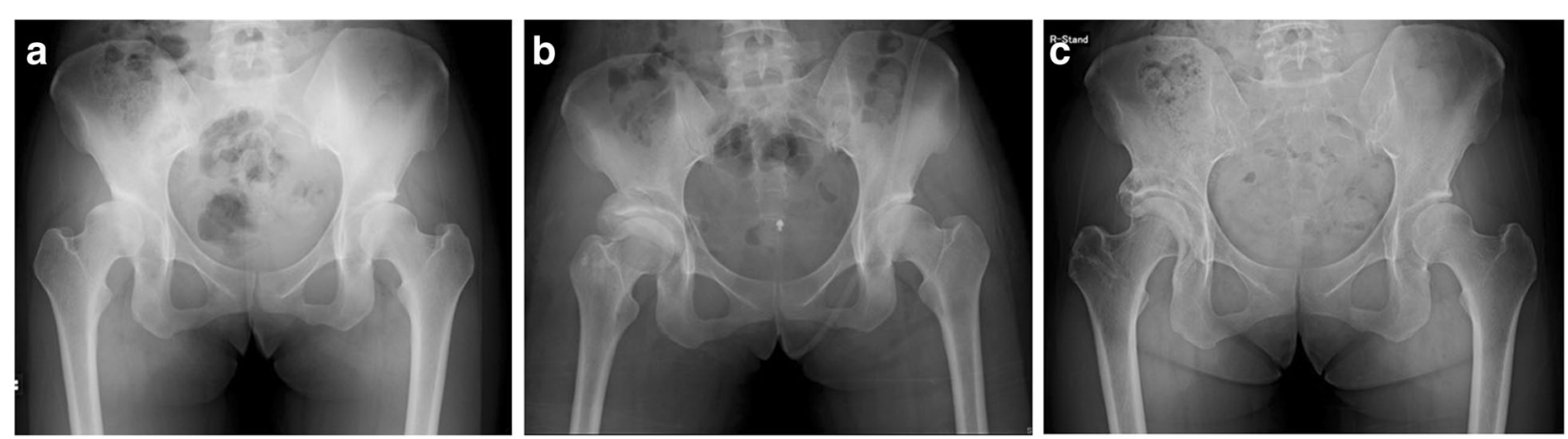

Fig. 5 Radiographic image of a 24-year-old woman treated with rotational acetabular osteotomy on her right hip. Plane radiography of the hip showed an AHD, however, the joint space was persisting (a). The coverage of femoral head was improved after RAO (b). c is the radiograph at 12 years after RAO, she did not have any symptoms on her right hip and there was no progression of joint space narrowing

reported that one of the factors predicting poor outcomes was age at the time of surgery [26, 27]. In accordance with these previous reports, age at the time of surgery in the current study is a significant risk factor for THA requirement or OA progression after RAO. As general knowledge, the incidence of articular cartilage degeneration of the hip joint is higher in older patients than in younger patients. Therefore, the outcomes of $\mathrm{RAO}$ would be poorer in older patients than in younger patients. Yuasa et al. reported that pre-existing OA was a significant predictor of failure of RAO [28]. In the current study, we classified all hips into 4 stages

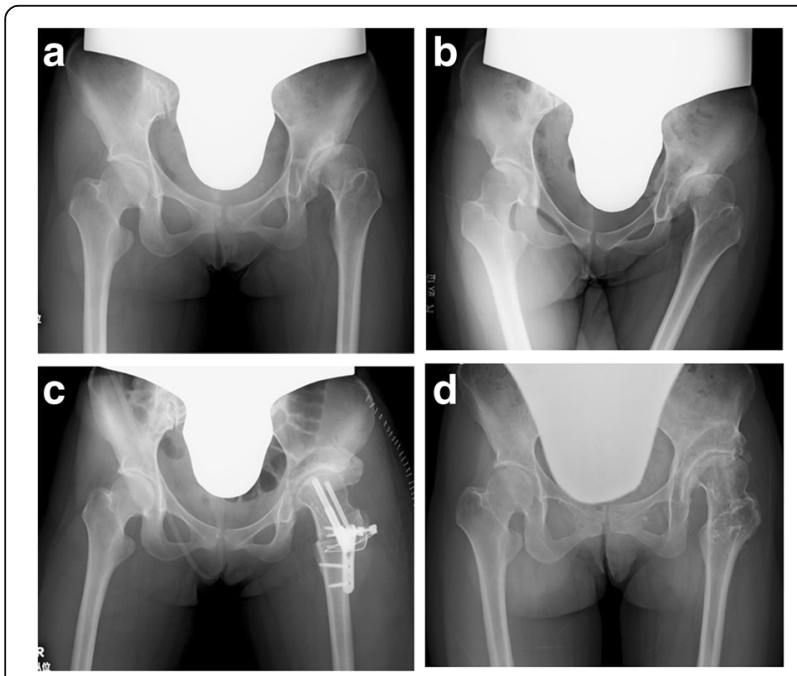

Fig. 6 Radiographic image of a 25-year-old woman treated with rotational acetabular osteotomy and valgus intertrochanteric osteotomy on her left hip. The preoperative radiographic image shows AHD with a deformity of the femoral head (a). The joint space becomes wider when the hip is adducted, and the position of the loading area of the femoral head becomes horizontal (b); thus, we performed RAO with valgus femoral osteotomy (c). There is no progression of OA 10 years after the surgery compared with the finding immediately after surgery, and she had no pain or any complaints on her left hip (d) according to the JOA classification, which is mainly determined using the JSW. However, based on the Cox regression analysis, the JSW itself was not a risk factor of THA or OA progression. In the current study, cases of hips with severe OA (JOA stage 4) were not included; this might be one of the reasons why the JSW did not reveal any significance in the results.

Several authors noted that excessive lateral and anterior correction in the acetabular osteotomy might lead to the cam or pincer type of femoroacetabular impingement (FAI) $[6,12]$, which may induce residual pain and limit hip motion. Chung et al. reported that in the hips with $\mathrm{CE}$ angles over $40^{\circ}$, there might be the risk of FAI, which may lead to OA progression [14]. Siebenrock et al. reported that $29 \%$ of the hips in their study had symptomatic impingement after Bernese periacetabular osteotomy (PAO), which is likely due to excessive acetabular roof correction [6]. Myers et al. reported the risk of secondary impingement after PAO [12]. Steppacher et al. also demonstrated a postoperative impingement sign as a predictor of poor outcome following PAO [27]. However, Yasunaga et al. found no significant correlations between a positive crossover sign and radiographic progression of OA, although anterior impingement signs increased after RAO [29]. In the current study, there was no significant difference between the non-overcorrection group and overcorrection group.

Furthermore, we assessed the time course change in the acetabular roof after RAO. This finding indicates that in overcorrected hips, the mechanical stress was not loaded on the edge of the rotated acetabular segment. As the result of the joint stress change, the edge of the acetabular segment might be remodeled.

Several authors reported the harmful influence of smoking on bone healing after fracture [30-34]. However, in the current study, there was no significant influence of smoking on either the result of RAO or union of a rotated acetabulum. This result might be due to the 
reasons following below; the osteotomy aspect was relatively large and rotated fragment and iliac bone were well fixed by using screws. Furthermore, blood flow of bone marrow of ilium abound which is favorite environment for bone remodeling.

In the current study, there was no significant difference in the survival rate among the patients whose hips were treated with different surgeries. This might be because the number of the hips treated with an additional femoral osteotomy was relatively too small to be used for comparison.

One limitation of this study was that we only addressed anteroposterior radiographs for the evaluation of hip status, despite the three-dimensional structure of the hips. However, in the current study, sufficient coverage was achieved, and the statistical survival analysis showed that there was no harmful influence in the overcorrection group compared to the nonovercorrection group. Another limitation was that most of the THAs were performed in older patients; thus, there might be a tendency that we subliminally avoided THAs in younger patients. This bias might have an influence on the result of the current study; however, the Cox regression analysis was performed not only for THA requirement but also for $\mathrm{OA}$ progression, and age at the time of surgery influenced both THA requirement and OA progression. Lastly, the study was a retrospective study with a relatively small number of patients. To determine adequate correction angles for the acetabular roof in RAO, prospective interventions in a larger population will be needed to elucidate accurate evaluations of long-term outcomes in RAO for future studies.

\section{Conclusion}

$\mathrm{RAO}$ is an effective surgical procedure for symptomatic patients with AHD that prevents OA progression and protects the hips from undergoing THA. In the current study, $23.3 \%$ of the hips showed OA progression, and THA was required in $7.7 \%$ of the hips after RAO during the 10-year follow-up. However, older patients have a higher risk for both OA progression and THA requirement. In RAO, acetabular correction should be sufficient to obtain an efficient femoral head coverage.

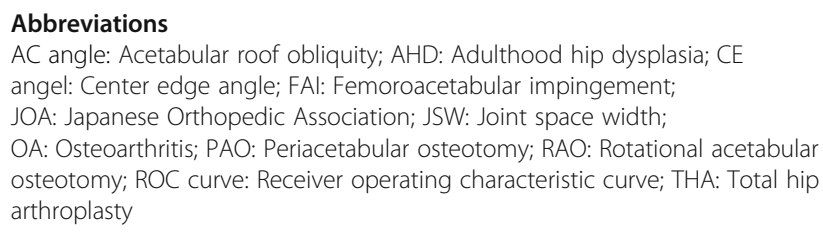

Acknowledgement

We thank all the patients involved in the study.
Availability of data and materials

Data will not be shared as consent for this was not included in the informed consent process.

\section{Authors' contributions}

MT: study design, interpreting the data and writing of the paper. YI: study design, critical revision. NK: analysis and interpretation of data. TT: analysis and interpretation of data, acquisition of data. HC: analysis and interpretation of data. HI: analysis and interpretation of data. TS: study design and critical revision. All authors read and approved the final manuscript.

\section{Competing interests}

The authors declare that they have no competing interests.

\section{Consent for publication}

Informed consent included consent for publication of quotations.

\section{Ethics approval and consent to participate}

Ethical approval for the study was obtained from the institutional review board of Yokohama City University (\#B170100004). Informed and written consent was obtained from all patients. We also obtained the consent from the representative cases in the current study for print and electronic publication of their X-ray films.

\section{Publisher's Note}

Springer Nature remains neutral with regard to jurisdictional claims in published maps and institutional affiliations.

Received: 23 January 2017 Accepted: 6 May 2017

Published online: 15 May 2017

\section{References}

1. Nakamura S, Ninomiya S, Nakamura T. Primary osteoarthritis of the hip joint in Japan. Clin Orthop Relat Res. 1989;241:190-6.

2. Bsila RS, Inglis $A E$, Ranawat CS. Joint replacement surgery in patients under thirty. J Bone Joint Surg Am. 1976;58(8):1098-104.

3. McAuley JP, et al. Total hip arthroplasty in patients 50 years and younger. Clin Orthop Relat Res. 2004;418:119-25.

4. Nakamura S, et al. Long-term outcome of rotational acetabular osteotomy: 145 hips followed for 10-23 years. Acta Orthop Scand. 1998;69(3):259-65.

5. Schramm M, et al. Long-term results of spherical acetabular osteotomy. J Bone Joint Surg Br. 1999;81(1):60-6.

6. Siebenrock KA, et al. Bernese periacetabular osteotomy. Clin Orthop Relat Res. 1999;363:9-20.

7. Nozawa M, et al. Rotational acetabular osteotomy for severely dysplastic acetabulum. Arch Orthop Trauma Surg. 2000;120(7-8):376-9.

8. Takatori $Y$, et al. Long-term results of rotational acetabular osteotomy in patients with slight narrowing of the joint space on preoperative radiographic findings. J Orthop Sci. 2001;6(2):137-40.

9. Ninomiya S, Tagawa H. Rotational acetabular osteotomy for the dysplastic hip. J Bone Joint Surg Am. 1984;66(3):430-6.

10. Hasegawa $Y$, et al. Eccentric rotational acetabular osteotomy for acetabular dysplasia: follow-up of one hundred and thirty-two hips for five to ten years. J Bone Joint Surg Am. 2002;84-A(3):404-10.

11. Yasunaga $Y$, et al. Rotational acetabular osteotomy for hip dysplasia: 61 hips followed for 8-15 years. Acta Orthop Scand. 2004;75(1):10-5.

12. Myers SR, Eijer H, Ganz R. Anterior femoroacetabular impingement after periacetabular osteotomy. Clin Orthop Relat Res. 1999;363:93-9.

13. Yamasaki T, et al. Inclusion and exclusion criteria in the diagnosis of femoroacetabular impingement. Arthroscopy. 2015;31(7):1403-10.

14. Chung CY, et al. Hip osteoarthritis and risk factors in elderly Korean population. Osteoarthritis Cartilage. 2010;18(3):312-6.

15. Freedman KS, Nelson NM, Feldman LL. Smoking initiation among young adults in the United States and Canada, 1998-2010: a systematic review. Prev Chronic Dis. 2012;9:E05.

16. Steel HH. Triple osteotomy of the innominate bone. J Bone Joint Surg Am. 1973:55(2):343-50.

17. Ganz R, et al. A new periacetabular osteotomy for the treatment of hip dysplasias. Technique and preliminary results. Clin Orthop Relat Res. 1988; 232:26-36. 
18. Hoaglund FT, et al. Diseases of the hip. A comparative study of Japanese Oriental and American white patients. J Bone Joint Surg Am. 1985;67(9): 1376-83.

19. Matsui $M$, et al. Early deterioration after modified rotational acetabular osteotomy for the dysplastic hip. J Bone Joint Surg Br. 1997;79(2):220-4.

20. Ninomiya S. Rotational acetabular osteotomy for the severely dysplastic hip in the adolescent and adult. Clin Orthop Relat Res. 1989;247:127-37.

21. Yasunaga $Y$, et al. Rotational acetabular osteotomy for advanced osteoarthrosis secondary to dysplasia of the hip. Results at 6-11 years postoperatively. Arch Orthop Trauma Surg. 1999;119(5-6):253-7.

22. Garbuz DS, Awwad MA, Duncan CP. Periacetabular osteotomy and total hip arthroplasty in patients older than 40 years. J Arthroplasty. 2008;23(7):960-3.

23. Hsieh $\mathrm{PH}$, et al. Comparison of periacetabular osteotomy and total hip replacement in the same patient: a two- to ten-year follow-up study. J Bone Joint Surg Br. 2009;91(7):883-8.

24. Sharifi E, et al. Cost-effectiveness analysis of periacetabular osteotomy. J Bone Joint Surg Am. 2008;90(7):1447-56.

25. Teratani T, et al. Periacetabular osteotomy in patients fifty years of age or older: surgical technique. J Bone Joint Surg Am. 2011;93 Suppl 1:30-9.

26. Kanezaki S, et al. Curtain osteophytes are one of the risk factors for the poor outcome of rotational acetabular osteotomy. Int Orthop. 2017;41(2):265-70

27. Steppacher SD, et al. Mean 20-year followup of Bernese periacetabular osteotomy. Clin Orthop Relat Res. 2008;466(7):1633-44.

28. Yuasa T, et al. Rotational acetabular osteotomy for acetabular dysplasia and osteoarthritis: a mean follow-up of 20 years. Arch Orthop Trauma Surg 2017:137(4):465-9.

29. Yasunaga $Y$, et al. Crossover sign after rotational acetabular osteotomy for dysplasia of the hip. J Orthop Sci. 2010;15(4):463-9.

30. Moller AM, et al. Effect of preoperative smoking intervention on postoperative complications: a randomised clinical trial. Lancet. 2002; 359(9301):114-7.

31. Cobb TK, et al. Cigarette smoking and nonunion after ankle arthrodesis. Foot Ankle Int. 1994;15(2):64-7.

32. Adams $\mathrm{Cl}$, Keating JF, Court-Brown CM. Cigarette smoking and open tibial fractures. Injury. 2001;32(1):61-5.

33. Schmitz MA, et al. Effect of smoking on tibial shaft fracture healing. Clin Orthop Relat Res. 1999;365:184-200.

34. Kyro A, et al. Are smokers a risk group for delayed healing of tibial shaft fractures? Ann Chir Gynaecol. 1993;82(4):254-62.

\section{Submit your next manuscript to BioMed Central and we will help you at every step:}

- We accept pre-submission inquiries

- Our selector tool helps you to find the most relevant journal

- We provide round the clock customer support

- Convenient online submission

- Thorough peer review

- Inclusion in PubMed and all major indexing services

- Maximum visibility for your research

Submit your manuscript at www.biomedcentral.com/submit

) Biomed Central 